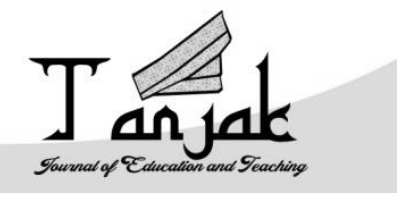

\author{
Tanjak: Journal of Education and Teaching \\ ISSN 2716-4098 (P) 2720-8966 (O) \\ Volume 2 Nomor 2, 2021
}

\title{
ANALISIS MOTIVASI BELAJAR MAHASISWA PADA MATA KULIAH STATISTIKA PENDIDIKAN DENGAN LEMBAR KERJA MAHASISWA BERBASIS INQUIRY
}

\author{
Sukma Adi Perdana ${ }^{1}$, Rezky Ramadhona ${ }^{2}$ \\ ${ }^{1}$ STAIN Sultan Abdurrahman KEPRI, Bintan, KEPRI, Indonesia, Sukma_adi@stainkepri.ac.id \\ ${ }_{2}^{2}$ Pendidikan Matematika UMRAH, Tanjungpinang, KEPRI, Indonesia, ramadhona@umrah.ac.id
}

Pengiriman: 10/12/2021; Diterima: 31/12/2021; Publikasi: 31/12/2021

DOI: https://doi.org/10.31629/ig.v2i1.271

\begin{abstract}
Abstrak
Motivasi belajar merupakan unsur yang sangat berpengaruh dalam keberhasilan peserta didik untuk mencapai tujuan pembelajaran. Oleh karena itu pendidik mempunyai peranan penting dalam meningkatkan motivasi belajar peserta didik. Usaha yang dilakukan pendidik yaitu merancang Lembar Kerja Mahasiswa (LKM). LKM yang dirancang berbasis Inquiry sehingga mahasiswa difasilitasi untuk menemukan konsep sendiri. Sehingga penelitian ini bertujuan untuk melihat motivasi belajar mahasiswa pada mata kuliah statistika pendidikan setelah belajar menggunakan LKM. Aspek motivasi yang dilihat yaitu aspek affect, self concept, dan effort.
\end{abstract}

Kata kunci: Motivasi Belajar; Statistika Pendidikan, Lembar Kerja Mahasiswa, Inquiry. 


\begin{abstract}
Learning motivation is a very influential element in the success of students to achieve learning objectives. Therefore, educators have an important role in increasing students' learning motivation. The effort made by educators is to design Student Worksheets. The Student Worksheets is designed based on Inquiry so that students are facilitated to find their own concepts. So this study aims to look at student learning motivation in the education statistics course after learning to use the Student Worksheets. Aspects of motivation that are seen are aspects of affect, self concept, and effort.
\end{abstract}

Keywords: Learning Motivation, Education Statistics, Student Worksheets, Inquiry.

\title{
Pendahuluan
}

Motivasi belajar sangat diperlukan seseorang dalam mencapai tujuan yang diinginkan. Sardiman (2007:73) mengatakan bahwa motivasi belajar merupakan keseluruhan daya penggerak di dalam diri siswa sehingga menimbulkan kegiatan belajar, dan memberikan arah pada kegiatan belajar, sehingga tujuan pembelajaran dapat tercapai. Ramadhona (2018) mengatakan bahwa mahasiswa yang belajar dengan motivasi yang tinggi memperoleh hasil yang lebih baik dibandingkan dengan mahasiswa yang mempunyai motivasi rendah. Oleh karena itu seorang pendidik harus mampu memotivasi siswa dalam pembelajaran agar tujuan pembelajaran dapat tercapai.

Statistika Pendidikan merupakan salah satu Mata Kuliah wajib yang harus ditempuh oleh Mahasiswa Program Studi Manajemen Pendidikan Islam. Mata Kuliah ini merupakan mata kuliah yang banyak mempelajari teori statistik yang dimanfaatkan untuk pengolahan data dalam dunia pendidikan. Sehingga perlu bimbingan dari pendidik agar peserta didik mampu menerapkan teori statistik tersebut.

Kenyataan yang terjadi, masih banyak mahasiswa yang kurang termotivasi untuk belajar statistika dalam hal ini adalah mata kuliah Statistika Pendidikan. Mereka beranggapan Statistika Pendidikan adalah mata kuliah yang sangat menakutkan dan membosankan. Mahasiswa kurang mau berusaha untuk menemukan sendiri jawaban dari soal yang diberikan, mereka suka menyalin pekerjaan teman atau menunggu pembahasan yang diberikan dosen. Jika hal ini dibiarkan maka mahasiswa tidak akan mampu memahami Statistika Pendidikan dengan baik, sehingga hasil belajar mereka pun akan rendah. Oleh karena itu perlu dirancang suatu pembelajaran yang melibatkan keaktifan mahasiswa, meningkatkan kreatifitas mahasiswa dan pola pikir mereka sehingga pembelajaran statistika terasa menyenangkan.

Metode inquiry sangat cocok dalam meningkatkan keaktifan siswa karena melalui metode inquiry peserta didik menemukan sendiri konsep yang dipelajarinya. Sanjaya (2011:196) mengatakan bahwa "Strategi pembelajaran inquiry adalah rangkaian kegiatan pembelajaran yang menekankan pada proses berpikir secara kritis dan analitis untuk mencari dan menemukan sendiri jawaban dari suatu masalah yang dipertanyakan". Dari pendapat tersebut terlihat bahwa metode inquiry lebih menekankan peran aktif mahasiswa baik fisik maupun mental dalam proses pembelajaran. Oleh karena itu pendidik berperan sebagai fasilitator yaitu mengarahkan dan membimbing peserta didik dalam melakukan penemuan-penemuan, sehingga motivasi belajar mereka dan pemahaman konsep mereka dapat meningkat.

Lembar Kerja Mahasiswa (LKM) dapat digunakan guru dalam memfasilitasi peserta didik untuk menemukan konsep yang dipelajari. Trianto (2010:111) menguraikan bahwa LKM adalah panduan untuk peserta didik dalam melakukan kegiatan penyelidikan atau pemecahan masalah. LKM berisi 
petunjuk-petunjuk kegiatan atau panduan yang digunakan untuk melakukan kegiatan penyelidikan atau pemecahan masalah. Oleh karena itu untuk meningkatkan motivasi belajar peserta didik dalam hal ini adalah mahasiswa maka perlu digunakan Lembar Kerja Mahasiswa berbasis Inquiry. Berdasarkan latar belakang tersebut di atas maka penulis merancang penelitian untuk melihat bagaimana Motivasi Belajar Mahasiswa Pada Mata Kuliah Statistika Pendidikan Dengan Lembar Kerja Mahasiswa Berbasis Inquiry

\section{Metode Penelitian}

Penelitian ini merupakan penelitian deskriptif dengan metode survey. Dimana data diperoleh dari angket yang diberikan kepada 21 mahasiswa yang mengambil mata kuliah Statistika Pendidikan. Selanjutnya angket dianalisis sesuai dengan aspek motivasi belajar yaitu aspek affect, self concept, dan effort.

\section{Hasil dan Pembahasan}

LKM merupakan salah satu sumber belajar mahasiswa yang dibuat oleh dosen, dimana melalui LKM mahasiswa dibimbing untuk menemukan konsep Statistika Pendidikan yang akan dipelajari. Sehingga apabila mereka sendiri yang terlibat dalam menemukan konsep maka mereka akan paham mengenai konsep yang telah dipelajarinya. Selama ini mahasiswa belajar Statistika langsung dijelaskan oleh dosen yang bersangkutan, sehingga konsep yang dijelaskan tidak bertahan lama dalam ingatan mereka. Selain itu mahasiswa merasa bosan dan kurang tertarik untuk belajar. Gambar 1 berikut adalah salah satu contoh bagian dari Draft LKM.

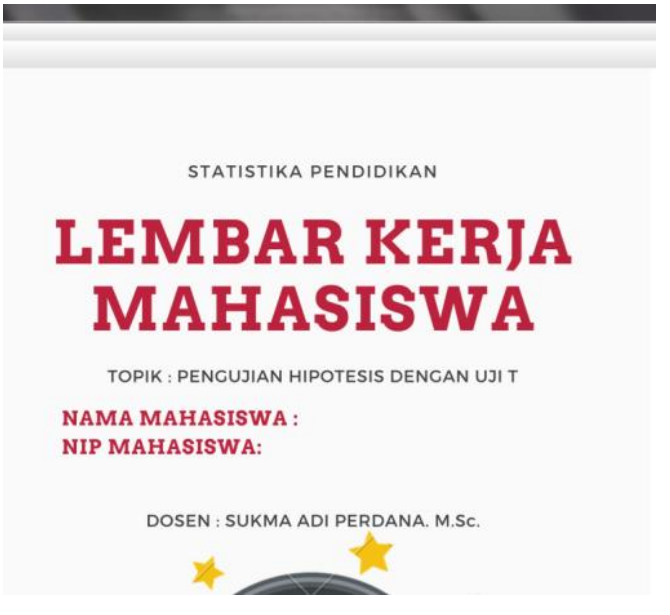

PENGUJAN HIPOTESIS DENGAN UJI T

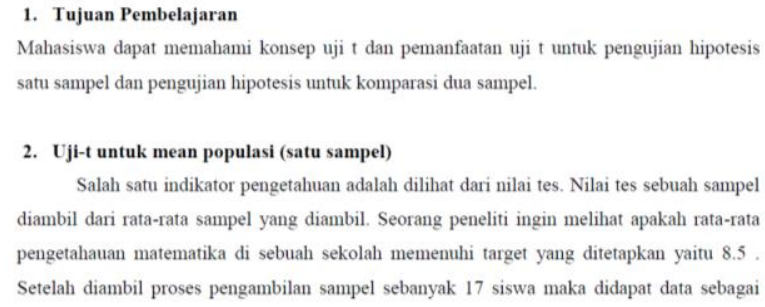

\section{Gambar 1 Contoh LKM.}

Lembar Kerja Mahasiswa (LKM) yang telah dirancang disesuaikan dengan RPS Mata Kuliah Statistika pendidikan, setelah itu LKM digunakan dalam proses pembelajaran. Untuk melihat bagaimana motivasi belajar mahasiswa setelah belajar menggunakan LKM maka mahasiswa diminta untuk mengisi angket motivasi belajar siswa.

Merancang angket motivasi belajar mahasiswa merupakan kegiatan yang dilaksanakan untuk merumuskan sebuah angket yang bertujuan untuk mengetahui motivasi mahasiswa setelah belajar 
menggunakan LKM. Kegiatan ini sangat penting sebagai indikator atau tolak ukur untuk melihat keberhasilan dari Lembar kerja Mahasiswa (LKM) berbasis inkuiri dalam meningkatkan motivasi belajar. Berikut contoh angket motivasi belajar yang telah dirumuskan seperti pada Gambar 2.

Jenis Kelamin :

Asal Kabupaten:

Isilah angket ini dengan jujur!

\begin{tabular}{|l|l|l|l|l|}
\hline No & \multicolumn{1}{|c|}{ Pernyataan } & S & KS & TS \\
\hline 1 & $\begin{array}{l}\text { Menurut saya pelajaran statistika } \\
\text { sangat membosankan }\end{array}$ & & \\
\hline 2 & $\begin{array}{l}\text { Saya senang mengerjakan soal yang } \\
\text { ada pada Lembar Kerja Mahasiswa } \\
\text { (LKM) }\end{array}$ & & & \\
\hline 3 & $\begin{array}{l}\text { Mengisi LKM membuat saya lebih } \\
\text { aktif }\end{array}$ & & & \\
\hline 4 & $\begin{array}{l}\text { Penggunaan LKM membuat saya } \\
\text { mengertidengan konsep yang } \\
\text { dipelajari }\end{array}$ & & & \\
\hline 5 & Soal yang ada di LKM bisa dipahami & & & \\
\hline 6 & $\begin{array}{l}\text { Saya mengerti belajar dengan } \\
\text { menggunakan LKM }\end{array}$ & & & \\
\hline 7 & $\begin{array}{l}\text { Saya dapat belajar secara mandiri } \\
\text { dengan menggunakan LKM }\end{array}$ & & & \\
\hline 8 & $\begin{array}{l}\text { Penggunaan LKM membantu proses } \\
\text { pembelajaran }\end{array}$ & & & \\
\hline 9 & $\begin{array}{l}\text { Saya berusaha mengisi LKM sesuai } \\
\text { kemammun cendiri }\end{array}$ & & & \\
\hline
\end{tabular}

Gambar 2 Contoh Angket Motivasi

Berkenaan untuk membuat angket motivasi belajar, maka indikator motivasi belajar yang akan dilihat harus dirumuskan terlebih dahulu. Untuk merumuskan indikator tersebut diawali dengan mencari referensi tentang motivasi belajar. Agar indikator yang dirumuskan benar-benar tepat mewakili motivasi belajar mahasiswa. Indikator yang dirumuskan adalah sikap terhadap statistika, pemahaman terhadap statistika, dan usaha dalam mengerjakan soal statistika. Indikator motivasi belajar dapat dilihat pada Tabel 1.

\section{Tabel 1 Indikator Angket Motivasi Belajar}

\begin{tabular}{|l|l|l|l|}
\hline No & Aspek & Indikator & Pernyataan \\
\hline 1 & Affect & sikap terhadap & 1. Menurut saya pelajaran statistika \\
& & statistika & sangat membosankan \\
& & & $\begin{array}{l}\text { 2. Saya senang mengerjakan soal yang } \\
\text { ada pada Lembar Kerja Mahasiswa } \\
\end{array}$ \\
& & (LKM) \\
& & $\begin{array}{l}\text { 3engisi LKM membuat saya lebih } \\
\text { aktif }\end{array}$ \\
& &
\end{tabular}




\begin{tabular}{|c|c|c|c|}
\hline 2 & $\begin{array}{l}\text { Self } \\
\text { Concept }\end{array}$ & $\begin{array}{l}\text { Pemahaman terhadap } \\
\text { statistika }\end{array}$ & $\begin{array}{l}\text { 4. Penggunaan LKM membuat saya } \\
\text { mengerti dengan konsep yang } \\
\text { dipelajari } \\
\text { 5. Soal yang ada di LKM bisa } \\
\text { dipahami } \\
\text { 6. Saya mengerti belajar dengan } \\
\text { menggunakan LKM }\end{array}$ \\
\hline 3 & Effort & $\begin{array}{l}\text { Usaha dalam } \\
\text { mengerjakan soal } \\
\text { statistika }\end{array}$ & $\begin{array}{l}\text { 7. Saya dapat belajar secara mandiri } \\
\text { dengan menggunakan LKM } \\
\text { 8. Penggunaan LKM membantu } \\
\text { proses pembelajaran } \\
\text { 9. Saya berusaha mengisi LKM sesuai } \\
\text { kemampuan sendiri } \\
\text { 0. Saya akan melewati soal-soal yang } \\
\text { tidak dimengerti yang ada pada } \\
\text { LKM }\end{array}$ \\
\hline
\end{tabular}

Setelah angket diisi oleh mahasiswa maka data dari angket tersebut diolah untuk melihat informasi berkaitan dengan motivasi mahasiswa dalam pembelajaran mata kuliah Statistika Pendidikan dengan menggunakan Lembar Kerja Mahasiswa atau LKM berbasis Inquiry. Berdasarkan hasil analisis maka dapat diambil kesimpulan bahwa untuk item 1, terdapat 71.4\% mahasiswa kurang setuju bahwa pelajaran statistika sangat membosankan, 19\% mahasiswa tidak setuju bahwa pelajaran statistika sangat membosankan dan 9.5\% mahasiswa yang setuju bahwa pelajaran statistika sangat membosankan. Item ke 2, 90.5\% mahasiswa senang mengerjakan soal yang ada pada LKM, dan 9.5\% mahasiswa kurang senang mengerjakan soal yang ada pada LKM. Item ke 3, 66.7\% mahasiswa setuju bahwa mengisi LKM membuat mereka lebih aktif, dan 33.3\% mahasiswa kurang setuju bahwa mengisi LKM membuat mereka lebih aktif. Secara keseluruhan untuk aspek affect yaitu sikap mahasiswa terhadap statistika sebesar 58.7\%. Gambar 3 merupakan diagram lingkaran dari aspek affect.

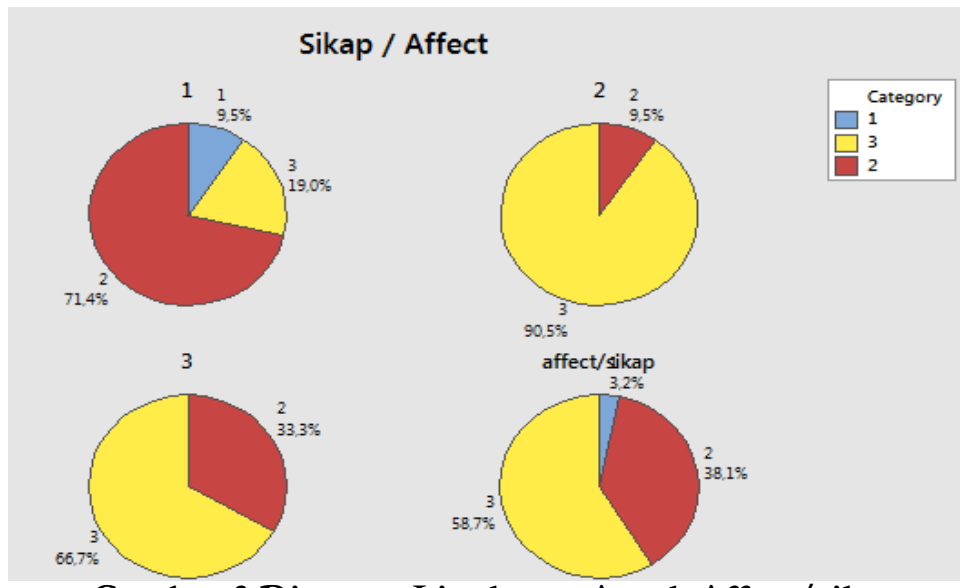

Gambar 3 Diagram Lingkaran Aspek Affect/sikap 
Hasil aspek self concept secara keseluruhan yaitu pemahaman mahasiswa terhadap statistika sebesar 55,6\%. Untuk item ke 4 terdapat 76.2\% mahasiswa setuju bahwa LKM membuat mereka mengerti dengan konsep yang dipelajari. Item ke 5 terdapat $42.9 \%$ mahasiswa setuju bahwa soal yang ada di LKM bisa dipahami. Item ke 6 terdapat 52.4\% mahasiswa mengerti belajar dengan menggunakan LKM. Gambar 4 merupakan diagram lingkaran dari aspek self concept.

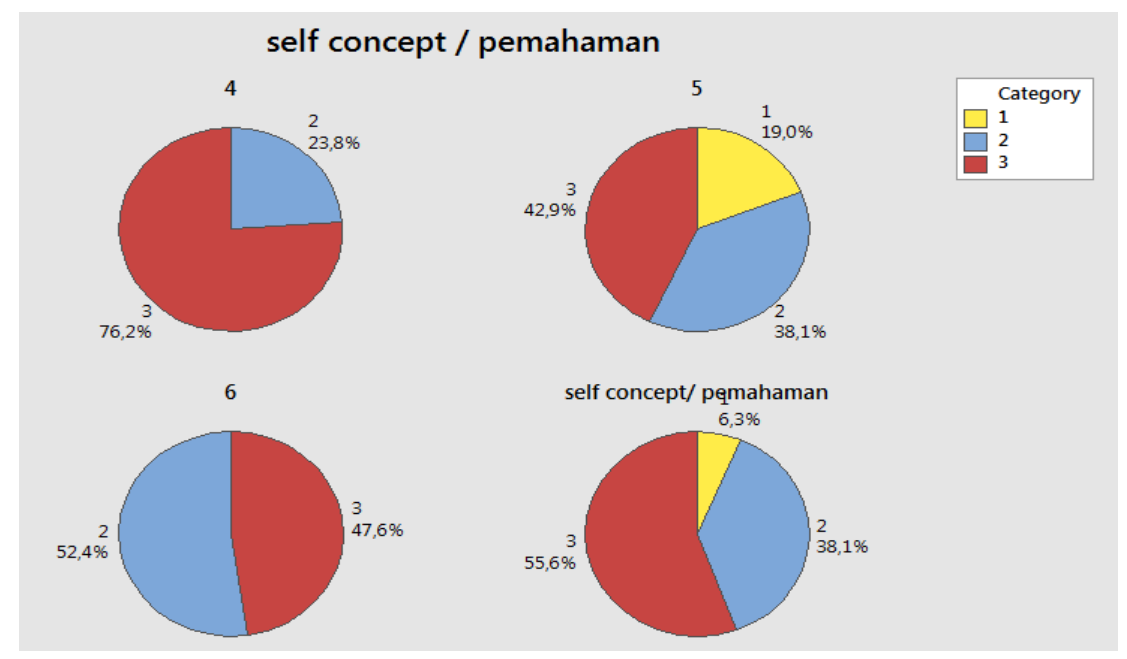

\section{Gambar 4 Diagram Lingkaran Aspek Self Concept}

Hasil aspek effort secara umum usaha mahasiswa dalam mengerjakan soal statistika sebesar 54,8\%. Untuk item 7 terdapat 52.4\% mahasiswa dapat belajar secara mandiri dengan menggunakan LKM. Item 8 sebesar 90.5\% mahasiswa setuju bahwa penggunaan LKM membantu proses pembelajaran. Item 9 sebesar $71.4 \%$ mahasiswa berusaha mengisi LKM sesuai kemampuan sendiri. Sedangkan Item 10 sebesar 81\% mahasiswa akan melewati soal-soal yang tidak dimengerti yang ada pada LKM. Gambar 5 merupakan diagram lingkaran untuk aspek effort.

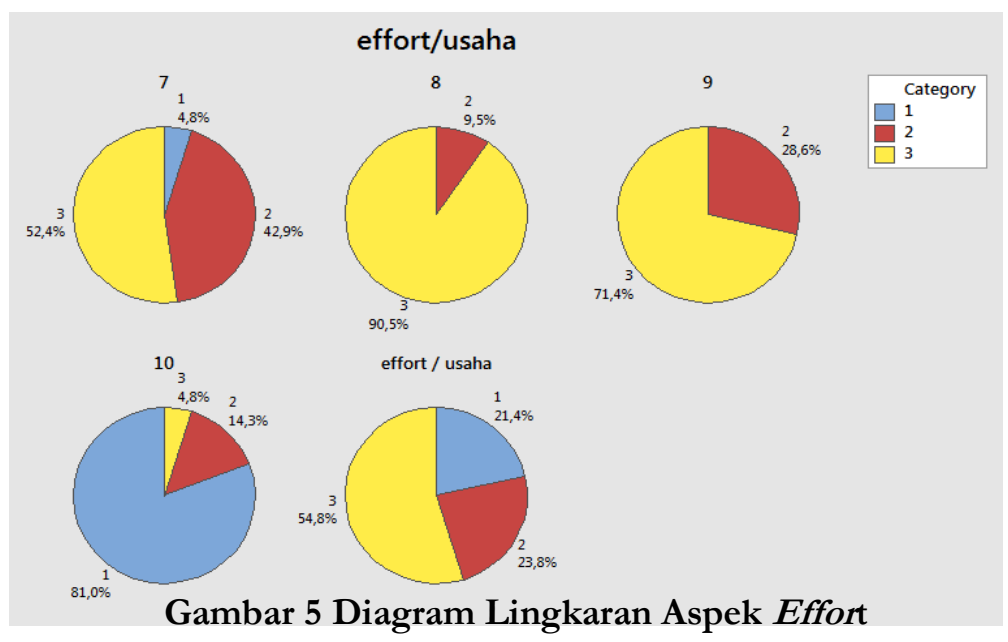




\section{Kesimpulan}

Berdasarkan hasil analisis angket, maka dapat disimpulkan bahwa mahasiswa termotivasi untuk belajar statistika dengan menggunakan LKM dilihat dari aspek affect, self concept, dan effort. Hal ini juga terlihat dari aspek motivasi belajar yaitu mahasiswa memiliki sikap yang baik terhadap materi Statistika, mereka tidak bosan belajar statistika dan senang mengerjakan soal-soal statistika. Kemudian dengan adanya LKM maka mahasiswa dapat memahami konsep statistika yang diajarkan sehingga mahasiswa mampu berusaha untuk menyelesaikan permasalahan yang diberikan terkait dengan konsep statistika dan mampu mencari solusi dari permasalahan tersebut.

\section{Ucapan Terimakasih}

Penulis mengucapkan terimakasih kepada pihak terkait seperti Program Studi Manajemen Pendidikan Islam STAIN Sultan Abdurrahman KEPRI atas dukungannya demi kesuksesan penelitian ini.

\section{Referensi}

Pannen, P. 2005. Pemanfaatan ICT dalam pembelajaran. Dipresentasikan pada Seminar Sun Commitment in Education and Research Industry, Jakarta, 29 Juni.

Permatasari, Intan, dkk. 2019. Pengembangan Bahan Ajar Ipa Berbasis Inkuiri Terintegrasi Sets (Science, Environment, Technology And Society) Pada Materi Sistem Reproduksi Manusia. Histogram: J.Pijar MIPA 13 (3), 2019, 74-78.

Prastowo, Andi. 2012. Panduan Kreatif Membuat Bahan Ajar Inovatif. Jogjakarta: DIVA Press.

Ramadhona, R\& Nurizzati. (2018). Pengembangan Lembar Kerja Mahasiswa Berbasis Inkuiri Mata Kuliah Matematika Umum untuk Mahasiswa Pendidikan Kimia. Jurnal Pendidikan Kiprah Vol VI(2),21-24.https://doi.org/10.31629/kiprah.v6i2.780

Sanjaya, Wina. (2011). Strategi Pembelajaran Berorientasi Standar Proses Pendidikan. Jakarta: Kencana Prenada MediaGroup.

Sardiman. 2009. Interaksi dan Motivasi Belajar Mengajar. Jakarta: Rajawali Pers.

Trianto. (2010). Mendesain Model Pembelajaran Inovatif dan Progresif. Jakarta:Prenada Media Group. 